\title{
Yeast extract-mediated elicitation of anti-cancerous compounds licoisoflavone $B$, licochalcone $A$, and liquirtigenin in callus cultures of Glycyrrhiza glabra
}

\author{
U. ViJayalakshmi, Abhilasha Shourie * \\ Department of Biotechnology, Faculty of Engineering \& Technology, \\ Manav Rachna International Institute of Research \& Studies, Faridabad, India
}

\begin{abstract}
Licoisoflavone B, licochalcone A, and liquirtigenin are important flavonoids found in the medicinal plant Glycyrrhiza glabra and are known for their preventive and therapeutic potential against cancer. Extraction of these flavonoids in commercially viable quantities is a challenging task. Therefore, an attempt has been made to elicit the production of these flavonoids in tissue cultures of $G$. glabra. We investigated the effect of the biotic elicitor yeast extract (YE) on the production of three flavonoids in $G$. glabra callus cultures grown in a previously standardized nutrient medium consisting of Murashige and Skoog's medium components supplemented with naphthalene acetic acid and benzyl amino purine. The YE elicitor was tested in the concentration range of $25-175 \mathrm{mg} / \mathrm{l}$. At each elicitor concentration, a time-course analysis was also performed to determine the effect of the duration of YE treatment on flavonoid production. The effect of YE on the key enzyme of the phenylpropanoid pathway, phenylalanine ammonia lyase (PAL), antioxidant enzymes, polyphenoloxidase (PPO), and peroxidase (POD) was also observed. The results revealed that $75 \mathrm{mg} / \mathrm{l}$ concentration of $\mathrm{YE}$ was most suitable for elicitation of biosynthesis of flavonoids in G. glabra cultures and more than a 2 -fold increase in the production of all the three flavonoids was obtained. The activities of the enzymes, PAL, PPO, and POD, also increased significantly, suggesting that the stress response was elicited by YE. These results provide evidence of activation of phenylpropanoid metabolism and regulation of its key enzymes by YE, eventually leading to enhanced production of anti-cancerous flavonoids licoisoflavone $\mathrm{B}$, licochalcone $\mathrm{A}$, and liquirtigenin.
\end{abstract}

Key words: Glycyrrhiza glabra, licoisoflavone B, licochalcone A, liquirtigenin, yeast extract, elicitation

\section{Introduction}

Cancer continues to remain the most daunting and life-threatening disease world-wide (Ma and $\mathrm{Yu}, 2006)$. Despite numerous advances and giant leaps in anticancer drug discovery, the search for safe and effective anticancer compounds still continues. Numerous studies have been conducted on the use of phytochemicals and natural compounds in the prevention of cancer $(\mathrm{Ma}$ and Yu, 2006; Wang et al., 2012; Iqbal et al., 2017; Jacobs, 2018). Glycyrrhiza glabra (G. glabra is a perennial herb known for its antioxidant, antitumor, anti-cancerous, and other health-protective bioactivities which are attributed to the presence of phytochemicals, especially flavonoids
(Vispute and Khopade, 2011). Licochalcone A, liquirtigenin, and licoisoflavone B are among the major flavonoids of $G$. glabra possessing anti-cancerous properties (Vispute and Khopade, 2011).

Licochalcone $\mathrm{A}$ is capable of inducing apoptosis and arresting cancer cell division and has been widely studied for its anti-cancerous activity and is now being used in cancer treatment (Shreya Dave et al., 2016). The compound has been reported to induce intrinsic and extrinsic apoptosis via erk $1 / 2$ and $\mathrm{p} 38$ phosphorylation-mediated trail expression in head and neck squamous carcinoma (Park et al., 2015). Licochalcone A is a selective c-Jun N-terminal kinase (JNK1) inhibitor which has a cri-

\footnotetext{
* Corresponding author: Department of Biotechnology, Faculty of Engineering \& Technology, Manav Rachna International Institute of Research and Studies, Sector-43, Faridabad, India, P.O. Box 121001; e-mail: aashourie@gmail.com
} 
tical role in inhibiting the growth of colon cancer cells and prevents pancreatic carcinogenesis (Yao et al., 2014). Licochalcone A prevents the growth of HepG2 cells through cell proliferation arrest and subsequent induction of apoptosis (Chen et al., 2017). It also causes G2 and late G1 phase arrests in androgen-independent PC-3 prostate cancer cells (Fu et al., 2004). Licochalcone $\mathrm{A}$ is reported to have exerted antitumor activity in studies involving bladder cancer cell lines, and mice models (Yang-Zhang et al., 2016).

Liquirtigenin belongs to the chiral flavanone family and its cancer-preventive mechanism has been studied by various researchers. Zhou et al. (2010) reported a significant in vivo inhibitory activity of liquirtigenin against hepatoma tumors. It has also exhibited inhibitory activity against tumor growth in the mouse model of Hela cells by inducing cellular apoptosis via the mitochondrial pathway, which is associated with p53 up-regulation, release of cytochrome $c$ and elevated activity of caspase-9 and caspase-3 (Liu et al, 2011). It was also reported to induce tumor cell death through mitogen - activated protein kinase mediated pathway in hepatocellular carcinoma cells in mice model (Wang et al., 2014).

Licoisoflavone B exhibits anti-mutagenic activity against carcinogenic mutagen N-methyl-N-nitrosourea and other $N$-nitroso compounds, by preventing DNA damage caused by them. (Inami et al., 2017). Isoflavones were reported to be involved in the modulation of cell proliferation, regulation of cell cycle, apoptosis, angiogenesis, and tumor cell metastasis (Wuttke et al., 2010).

The three flavonoids, licoisoflavone B, licochalcone A, and liquirtigenin are much-needed due to their potential medicinal properties and prospective use as anticancerous drugs. These flavonoids are produced mainly in the roots of G. glabra plants and are extracted usually after their complete uprooting (Vijayalakshmi and Shourie, 2017). Their yield, however, is not very consistent because it is affected by numerous environmental factors (Panche et al., 2016). Thus, the production of these flavonoids in tissue cultures can be seen as a promising option. This research focuses on obtaining desirable quantities of licoisoflavone B, licochalcone A, and liquirtigenin from callus cultures of $G$. glabra by using yeast extract (YE) elicitation and presents the very first report on simultaneous elicitation of three flavonoids. This study also gives an insight into probable mechanisms involved in the elicitation of G. glabra tissue cultures.

\section{Materials and methods}

\section{Callus culture}

Authentic G. glabra plants were obtained from the forest nursery, Faridabad in the month of August and the young leaves were used as explants. The callus culture was developed using a previously standardized culture medium (Vijayalakshmi and Shourie, 2016a) which is further referred to in this paper as G. glabra callus culture (GCC) medium. All the inoculations were carried out in a laminar air flow chamber and the cultures were incubated at a controlled light intensity of $2000 \mathrm{Lux}$ for a 16-hour light and 8-hour dark photoperiod at $25 \pm 2{ }^{\circ} \mathrm{C}$. Callus growth was assessed by measuring the weight of the callus at the time of initiation and at the end of each week after inoculation for 8 weeks. Assessment of callus growth was done on the basis of growth index (GI).

$\mathrm{GI}=($ final fresh weight - initial fresh weight $) /$

/ initial fresh weight

(Vijayalakshmi and Shourie, 2016a).

\section{Elicitor preparation and elicitation of callus cultures of G. glabra}

YE was prepared by the ethanol precipitation method (Chen and Chen, 2001), in which YE was first dissolved in distilled water and then precipitated in $80 \%$ ethanol. After incubation at $4{ }^{\circ} \mathrm{C}$ for 4 days, the precipitate was redissolved in distilled water, autoclaved at $121^{\circ} \mathrm{C}$ for $15 \mathrm{~min}$ and the final volume was adjusted to obtain the required YE concentrations ranging from $25 \mathrm{mg} / 1$ to $175 \mathrm{mg} / \mathrm{l}$. In all the experiments, YE was supplemented to the standardized GCC medium in defined doses.

\section{Extraction, qualitative analysis, and quantitative estimation of flavonoids}

The elicited and non-elicited callus cultures were harvested, shade-dried, powdered in a mechanical grinder and extracted in $70 \%$ ethanol at $85^{\circ} \mathrm{C}$ for $4 \mathrm{~h}$ with constant agitation. The extract was filtered and re-extracted two times under the same conditions. Each time the filtrate was collected in the same flask and partitioned using the following solvents: petroleum ether, diethyl ether, and ethyl acetate. A qualitative analysis and a quantitative estimation of licoisoflavone $\mathrm{B}$, licochalcone $\mathrm{A}$, and liquirtigenin in the extracts were done by gas chromatographymass spectrometry (GC-MS) analysis. The samples were derivatized with trimethylsilyl prior to injection in the chromatography column and separation was done using 
helium as a carrier gas at a flow rate of $1.21 \mathrm{ml} / \mathrm{min}$, $85.4 \mathrm{kPa}$ inlet pressure and $250^{\circ} \mathrm{C}$ temperature. Mass spectra were recorded at $70 \mathrm{eV}$ with a scan interval of $0.5 \mathrm{~s}$ (Vijayalakshmi and Shourie, 2016b).

\section{Phenylalanine ammonia-lyase (PAL) assay}

PAL was extracted from callus tissues by homogenizing it with $0.05 \mathrm{M}$ Tris- $\mathrm{HCl}(\mathrm{pH} 8.0$ ), $0.8 \mathrm{mM} \beta$-mercaptoethanol, and $1 \% \mathrm{w} / \mathrm{v}$ polyvinyl pyrrolidone. Substrate phenylalanine $(10 \mathrm{mM})$ was added to the enzyme extract and incubated for $1 \mathrm{~h}$ at $37^{\circ} \mathrm{C}$. The reaction was stopped by the addition of $0.1 \mathrm{ml} 1 \mathrm{~N} \mathrm{HCl}$, and absorbance was read at $290 \mathrm{~nm}$ in ultraviolet - visible spectrophotometer. The enzyme activity was expressed in terms of the formation of $1 \mu \mathrm{M}$ of trans-cinnamic acid per min per mg of enzyme (Syklowska-Baranek et al., 2012). The protein content was determined according to the Bradford method (Bradford, 1976) with a standard curve prepared using bovine serum albumin (BSA) (Sigma-Aldrich).

\section{Polyphenoloxidase (PPO) enzyme assay}

The PPO enzyme assay was carried out according to the method described by Soffan et al. (2014). One gram of callus was homogenized in $2 \mathrm{ml}$ of $0.1 \mathrm{M}$ sodium phosphate buffer ( $\mathrm{pH}$ 6.5). The homogenate was centrifuged at $20000 \mathrm{rpm}$ for $15 \mathrm{~min}$. The supernatant served as enzyme extract.

The reaction mixture consisted of $0.1 \mathrm{M}$ sodium phosphate buffer ( $\mathrm{pH} 6.5$ ), $0.1 \mathrm{M}$ catechol as a substrate, and the enzyme extract obtained from the callus tissue. The PPO activity was expressed as change in absorbance per min per mg of protein at $495 \mathrm{~nm}$ at $30 \mathrm{~s}$ intervals for $5 \mathrm{~min}$. The protein content was determined according to the Bradford method (Bradford, 1976), with a standard curve prepared using bovine serum albumin.

\section{Peroxidase (POD) enzyme assay}

Peroxidase activity was determined by measuring the appearance of brown color resulting from oxidation of guaiacol as a substrate in the presence of hydrogen peroxide according to the method of Zieslin and Ben-Zaken (1993). The reaction mixture consisting of $0.02 \mathrm{M}$ guaiacol, $0.38 \mathrm{M} \mathrm{H}_{2} \mathrm{O}_{2}$, and $0.2 \mathrm{M}$ sodium phosphate buffer (pH 5.8), was added to $50 \mu$ of enzyme extract. The absorbance was measured after every $1 \mathrm{~min}$ for $5 \mathrm{~min}$ at $470 \mathrm{~nm}$, and enzyme activity was determined on the basis of the increase in absorbance by 1.0 at $470 \mathrm{~nm}$ per min at $25^{\circ} \mathrm{C}$ and the specific activity of POD was expressed as unit per mg protein. The protein content was determined according to the Bradford method (Bradford, 1976), with a standard curve prepared using BSA.

\section{2,2-diphenyl-1-picrylhydrazyl (DPPH) radical scavenging activity}

The antioxidant activity of the callus extracts was measured on the basis of its $\mathrm{DPPH}^{\circ}$ radical scavenging potential as outlined by $\mathrm{Yu}$ et al. (2003). Calli were incubated with $3.5 \mathrm{ml}$ of freshly prepared DPPH methanol solution in a dark at room temperature for $30 \mathrm{~min}$, and the absorbance was measured at $517 \mathrm{~nm}$ using a spectrophotometer. The inhibition of $\mathrm{DPPH}^{*}$ in percentage ( $\mathrm{I} \%$ ) of each sample was calculated from the decrease of absorbance according to the following formula (Savatovic et al., 2012):

$$
\mathrm{I} \%=\left[\left(\mathrm{A}_{\text {blank }}-\mathrm{A}_{\text {sample }}\right) / \mathrm{A}_{\text {blank }}\right] \times 100
$$

Where, $A_{\text {blank }}$ is the absorbance of the blank consisting of DPPH in aqueous methanol; $\mathrm{A}_{\text {sample }}$ is the absorbance of different extracts.

\section{Reducing power assay}

Callus extracts were tested for their reducing power by assessing the amount of reduction of the $\mathrm{Fe}^{3+}$ into $\mathrm{Fe}^{2+}$ according the method described by Hinneburg et al. (2006). One $\mathrm{ml}$ of enzyme extracts was mixed with $200 \mathrm{mM}$ phosphate buffer ( $\mathrm{pH} 6.6)$ and $1 \%$ potassium ferricyanide, and incubated at $50^{\circ} \mathrm{C}$ for $20 \mathrm{~min}$. The mixture was supplemented with $10 \%$ trichloroacetic acid and centrifuged at $3000 \mathrm{rpm}$ for $10 \mathrm{~min}$. An aliquot of supernatant was mixed with $2.5 \mathrm{ml}$ of distilled water and $0.1 \%$ $\mathrm{FeCl}_{3}$ and the absorbance was measured spectrophotometrically at $700 \mathrm{~nm}$. A higher absorbance of the reaction mixture indicated a higher reductive potential. The absorbance of the reaction mixture was considered as a direct measure of its reducing power.

\section{Statistical analysis}

All data were analyzed by one-way ANOVA. Tukey's test was used to separate the means, where the effects of the treatments were statistically significant $(P \leq 0.05)$. Error bars of all the graphs represent standard deviation. Columns sharing the same letters are not significantly different. 


\section{Results and discussion}

Elicitation of anticancerous compounds licochalcone $A$, liquirtigenin, and licoisoflavone $B$

This is the very first report of the elicitation of anticancerous compounds licoisoflavone $\mathrm{B}$, licochalcone $\mathrm{A}$, and liquirtigenin from $G$. glabra callus cultures. The retention time, fragmentation pattern $(\mathrm{m} / \mathrm{z})$ and significant ions from mass spectra of licoisoflavone $\mathrm{B}$, licochalcone A, and liquirtigenin obtained through GC-MS analysis of G. glabra callus are shown in Table 1.

The production of all the three compounds was significantly enhanced by eliciting the callus cultures with YE. Licoisoflavone $\mathrm{B}$, licochalcone $\mathrm{A}$, and liquirtigenin production increased with increasing concentrations of the YE and maximized at $75 \mathrm{mg} / \mathrm{l} \mathrm{YE} \mathrm{treatment} \mathrm{(Table} \mathrm{2).}$ There was a remarkable increase in the licoisoflavone $\mathrm{B}$ production (9.86-fold) as compared to that of the untreated callus, whereas the production of licochalcone $A$ and liquirtigenin showed an increase of 2 and 2.69-folds, respectively (Fig. 1). Beyond $75 \mathrm{mg} / 1 \mathrm{YE}$ concentration, the production of flavonoids was either not much affected, or decreased. The optimum YE concentration that significantly favored the production of the three anti-cancerous flavonoids was found to be $75 \mathrm{mg} / \mathrm{l}$. Further increasing the concentrations of YE for elicitation did not affect the flavonoid production in callus cultures of G. glabra, and the use of more than $150 \mathrm{mg} / \mathrm{l} \mathrm{YE}$ inhibited the growth of callus.

YE has been used as an elicitor in many studies, to enhance the production of various secondary metabolites in tissue cultures of G. glabra and Glycyrrhiza echinata. Flavonoid production in cultured cells of $G$. echinata was reported to be promoted by the addition of YE (Ayabe et al., 1986). Hyashi et al. (2003 and 2005) reported that YE promoted butulinic acid accumulation in cultured cells of G. glabra. In many studies, YE has also been used to enhance the production of various secondary metabolites in tissue cultures of other plants (Cakir and Ari, 2008; Hong et al., 2012; EI-Nabarawy et al., 2015). These reports also state that very high concentrations of YE do not favor secondary metabolite production which is in accordance with the results obtained in this study.

The production of anti-cancerous compounds licoisoflavone B, licochalcone A, and liquirtigenin in G. glabra callus was not only influenced by the elicitor concentration but was also found to depend on the time duration of elicitor treatment (Vijayalakshmi and Shourie, 2015). This led us to perform the timecourse analysis of flavonoid production at all the tested concentrations of YE (Fig. 2). In vitro production of all three flavonoids started within two weeks of the elicitor treatment as compared to the control. Maximum production was achieved at 6 weeks, beyond which a slow decrease in the production of licoisoflavone $\mathrm{B}$, licochalcone $\mathrm{A}$, and liquirtigenin was observed. Moreover, samples treated with $125 \mathrm{mg} / \mathrm{l}$ and $150 \mathrm{mg} / \mathrm{l}$ of yeast extracts showed a drastic decrease (2-fold) in liquirtigenin production after 7 weeks. These results indicate that prolonged stress due to elicitor treatment adversely affects the viability of callus cells, leading to the deterioration of the culture and a consequent decrease in metabolite production. A feedback inhibition of the flavonoid biosynthesis pathway by the three product flavonoids licoisoflavone $\mathrm{B}$, licochalcone $\mathrm{A}$, and liquirtigenin can also be one of the probable reasons for the reduction in flavonoid production.

\section{Effect of YE on callus growth}

The addition of YE to the GCC medium had a remarkable effect on callus growth. The GI of callus was significantly increased when treated with $\mathrm{YE}$ within the concentration range of $25-150 \mathrm{mg} / \mathrm{l}$, as compared to that of untreated cultures (Fig. 3). A noticeably high GI (9.42) was obtained with $150 \mathrm{mg} / \mathrm{l} \mathrm{YE}$ which was obtained at 6 weeks of culture. Due to its high amino acid content $\mathrm{YE}$ is commonly used as a supplement to promote plant growth (George et al., 2008), and as a biotic elicitor for the induction and enhancement of secondary metabolite production (Naik and Al-Khayri, 2016). In this study, YE concentration up to $150 \mathrm{mg} / \mathrm{l}$ promoted the callus growth but a higher concentration $(175 \mathrm{mg} / \mathrm{l})$ inhibited further growth, and decreased GI (GI = 5.54), which was probably due to nitrogen toxification and chlorosis, indicating biotic stress in the callus (Abass, 2016).

The callus treated with YE concentration of $175 \mathrm{mg} / \mathrm{l}$ showed signs of serious morphological abnormalities such as chlorosis, tissue browning, and rapid senescence. Such types of abnormalities were also detected in tissue cultures of Curcuma mangga (Abraham et al., 2011) and in Glehnia littoralis tissue cultures after they were exposed to higher concentrations of $\mathrm{YE}$, while the production of secondary metabolite caffeic acid and ferulic acid increased in appreciable amounts (more than 2-fold) (Ishikava et al, 2007). 
Table 1. Retention time, fragmentation pattern $(\mathrm{m} / \mathrm{z})$, and significant ions from mass spectra of licoisoflavone $\mathrm{B}$, licochalcone $\mathrm{A}$, and liquirtigenin

\begin{tabular}{l|c|c|c}
\hline \multicolumn{1}{c|}{ Compound } & $\begin{array}{c}\mathrm{RT} \\
{[\mathrm{min}]}\end{array}$ & $\begin{array}{c}\text { Molecular ion } \\
{\left[\mathrm{M}^{+}\right]}\end{array}$ & $\begin{array}{c}\text { Significant ions } \\
{[\mathrm{m} / \mathrm{z}]}\end{array}$ \\
\hline Licoisoflavone B & 27.1 & 352 & $139,151,165,193,222,250,27,280,352$ \\
\hline Licochalcone A & 30.3 & 338 & $121,177,189,277,307,308,323,338$ \\
\hline Liquirtigenin & 30.7 & 256 & $39,51,69,104,124,152,179,238,256$ \\
\hline
\end{tabular}

Table 2. Influence of different concentrations of yeast extract (YE) on the production of flavonoids licoisoflavone B, licochalcone A, and liquirtigenin in a callus culture of $G$. glabra with maximum growth index

\begin{tabular}{c|c|c|c}
\hline $\begin{array}{c}\text { YE } \\
\begin{array}{c}\text { concentration } \\
{[\mathrm{mg} / \mathrm{l}]}\end{array}\end{array}$ & $\begin{array}{c}\text { Licoisoflavone B } \\
{[\text { Peak area \%] }}\end{array}$ & $\begin{array}{c}\text { Licochalcone A } \\
{[\text { Peak area \%] }}\end{array}$ & $\begin{array}{c}\text { Liquirtigenin } \\
\text { [Peak area \%] }\end{array}$ \\
\hline 0 & $0.18 \pm 0.013^{\mathrm{a}}$ & $8.43 \pm 1.131^{\mathrm{a}}$ & $2.05 \pm 0.417^{\mathrm{a}}$ \\
\hline 25 & $0.812 \pm 0.226^{\mathrm{b}}$ & $13.02 \pm 2.253^{\mathrm{b}}$ & $2.60 \pm 0.525^{\mathrm{b}}$ \\
\hline 50 & $1.384 \pm 0.295^{\mathrm{c}}$ & $14.15 \pm 2.173^{\mathrm{b}}$ & $3.58 \pm 0.311^{\mathrm{c}}$ \\
\hline 75 & $1.776 \pm 0.204^{\mathrm{d}}$ & $16.86 \pm 4.524^{\mathrm{c}}$ & $5.51 \pm 0.403^{\mathrm{d}}$ \\
\hline 100 & $1.654 \pm 0.132^{\mathrm{de}}$ & $15.52 \pm 2.452^{\mathrm{d}}$ & $4.73 \pm 0.254^{\mathrm{e}}$ \\
\hline 125 & $1.614 \pm 0.411^{\mathrm{de}}$ & $15.23 \pm 3.496^{\mathrm{d}}$ & $4.51 \pm 0.278^{\mathrm{e}}$ \\
\hline 150 & $1.60 \pm 0.261^{\mathrm{e}}$ & $14.73 \pm 1.266^{\mathrm{b}}$ & $4.49 \pm 0.726^{\mathrm{e}}$ \\
\hline 175 & $1.43 \pm 0.231^{\mathrm{f}}$ & $9.23 \pm 2.781^{\mathrm{a}}$ & $3.78 \pm 0.887^{\mathrm{c}}$ \\
\hline
\end{tabular}

Values represent mean $\pm \mathrm{SD}(n=3)$; means followed by different letters are significantly different at $\alpha=0.05$

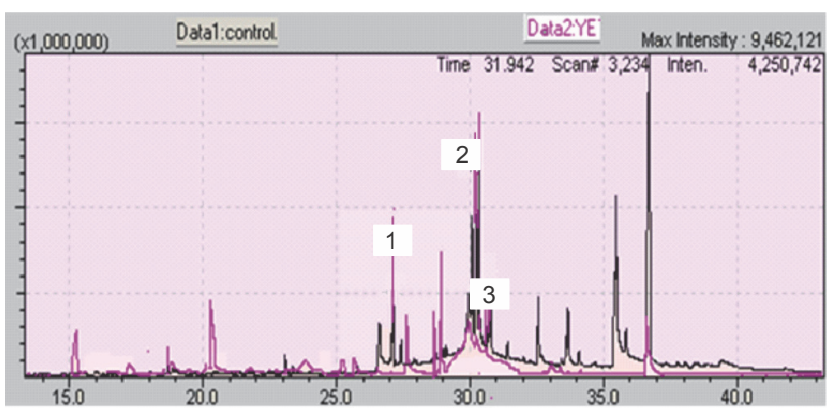

Fig. 1. Comparative gas chromatography mass spectrometry profile of control (black) and treated (pink) $(75 \mathrm{mg} / 1$ yeast extract (YE) samples of Glycyrrhiza glabra callus; peaks 1, 2, and 3 represent licoisoflavone B $(\mathrm{RT}=27.1)$, licochalcone A $(\mathrm{RT}=30.3)$, and liquirtigenin $(\mathrm{RT}=30.7)$

\section{Effect of the YE on PAL}

PAL is an entry-point enzyme of the phenylpropanoid pathway (Zhang and Liu, 2015). An increase in PAL activity in plants has been shown to be an immediate response to pathogens, elicitors, and adverse environmental factors (Zhang and Liu, 2015). A rapid synthesis of phenolic compounds, including flavonoids, is sugges- ted to be an important plant defense response against such factors (Kulbat, 2016); therefore, it is expected that PAL activity changes in plants will affect phenylpropanoid biosynthesis.

In this study, a significant increase in PAL activity in the samples as compared to that of control $(P<0.05)$ was observed, especially at concentrations $100 \mathrm{mg} / \mathrm{l}$, $125 \mathrm{mg} / \mathrm{l}$, and $150 \mathrm{mg} / \mathrm{l}$ with PAL activity of $9.32,9.77$, and $9.76 \mathrm{U} \mathrm{mg}^{-1}$ protein, respectively (Fig. 4A). The time-course analysis of PAL activity for all elicitor treatments revealed that the maximum activity $\left(9.77 \mathrm{U} \mathrm{mg}^{-1}\right.$ protein) was attained with $125 \mathrm{mg} / \mathrm{l} \mathrm{YE}$ treatment at 6 weeks (Fig. 4B). An increase in PAL activity could often be considered as a marker of plant cell response towards stress induced by exogenous treatment of $\mathrm{YE}$, which is known to elicit certain genes involved in flavonoid synthesis (Ramakrishna and Ravishankar, 2011).

\section{Effect of the YE on PPO and POD activities}

PPO participates in defense reactions that induce resistance to biotic and abiotic stresses in plants (Schneider and Ullrich, 1994; Stewart et al., 2001). The changes 

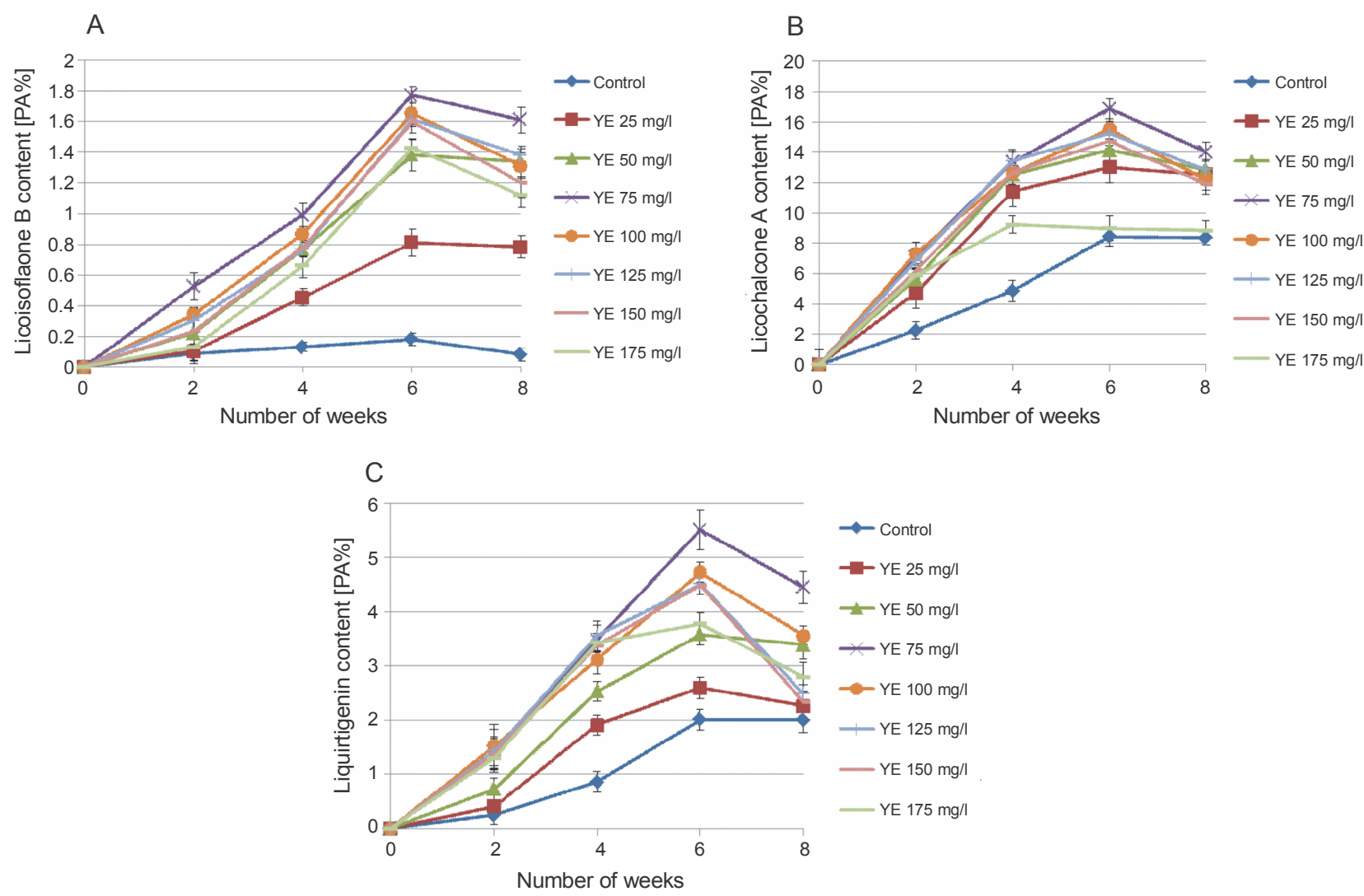

Fig. 2. Time-course analysis of A) licoisoflavone B; B) licochalcone A; C) liquirtigenin production at different concentrations of yeast extract treatment

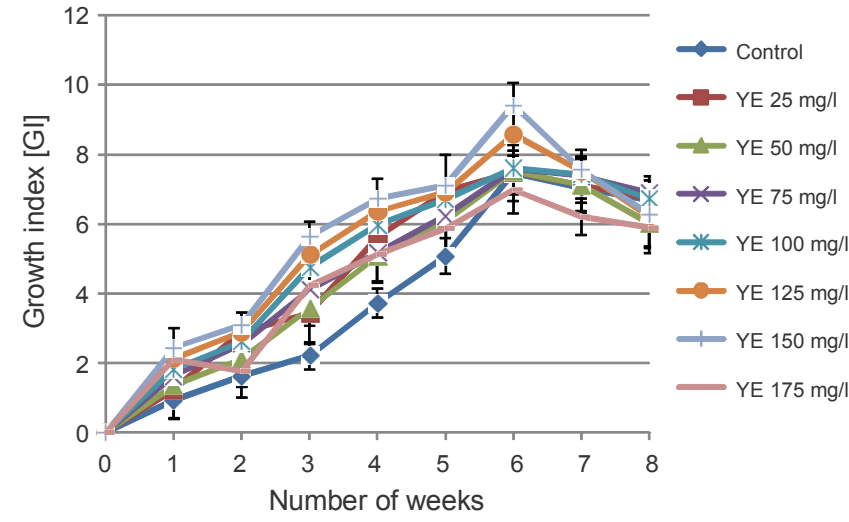

Fig. 3. Effect of different concentrations of $\mathrm{YE}$ on callus growth; values are represented as mean $\pm \mathrm{SD}(n=20)$; values marked with different letters are significantly different from each other and from the control

in $\mathrm{PPO}$ activity in response to $\mathrm{YE}$ treatment are shown in Figure 5. PPO activity increased as compared to that of control in all the treated callus cultures. The maximum increase in the PPO enzyme activity $\left(4.74 \mathrm{U} \mathrm{mg}^{-1}\right.$ protein) was observed in callus samples elicited with $75 \mathrm{mg} / \mathrm{l} \mathrm{YE}$, followed by a very slight decrease at higher concentrations of the elicitor. At $150 \mathrm{mg} / \mathrm{l}\left(3.25 \mathrm{U} \mathrm{mg}^{-1}\right.$ protein), and $175 \mathrm{mg} / 1$ (2.71 $\mathrm{U} \mathrm{mg}^{-1}$ protein) of YE supplementation, the decrease was observed quite early, within 4 weeks.

POD is another antioxidant enzyme that contributes to the formation of defense barriers against stress by scavenging hydrogen peroxide and reducing oxidative stress (Pourcel et al., 2007). In GCCs treated with YE, the POD activity was greatly affected at all elicitor concentrations. There was a gradual increase in the peroxidase activity with increasing concentrations of YE from $25 \mathrm{mg} / \mathrm{l}$ up to $125 \mathrm{mg} / \mathrm{l}$. The POD activity nearly doubled (20 units $\mathrm{mg}^{-1}$ protein) at $125 \mathrm{mg} / \mathrm{l} \mathrm{YE}$ when compared to that of control (9.56 $\mathrm{U} \mathrm{mg}^{-1}$ protein). Peroxidase activity started decreasing at higher concentrations of $\mathrm{YE}$ $(150 \mathrm{mg} / \mathrm{l}$ and $175 \mathrm{mg} / \mathrm{l})$ to $16.5 \mathrm{U} \mathrm{mg}^{-1}$, and $13.2 \mathrm{U} \mathrm{mg}^{-1}$ protein, respectively. An increase in peroxidase activity during interactions with elicitors is well documented and some peroxidases have been spatially and temporally associated with different types of biotic and abiotic stress responses (Adam et al., 1995; Milosevic and Slusarenko, 1996; Chittoor et al., 1997). 


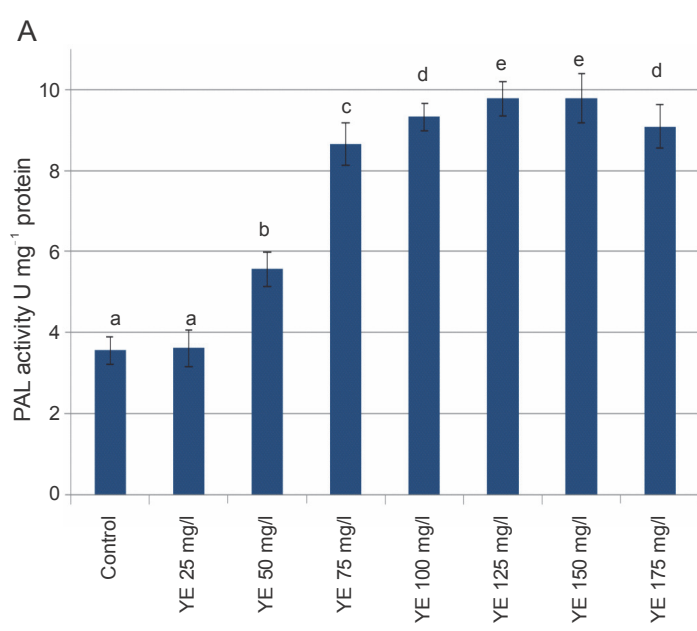

B

Yeast extract concentration

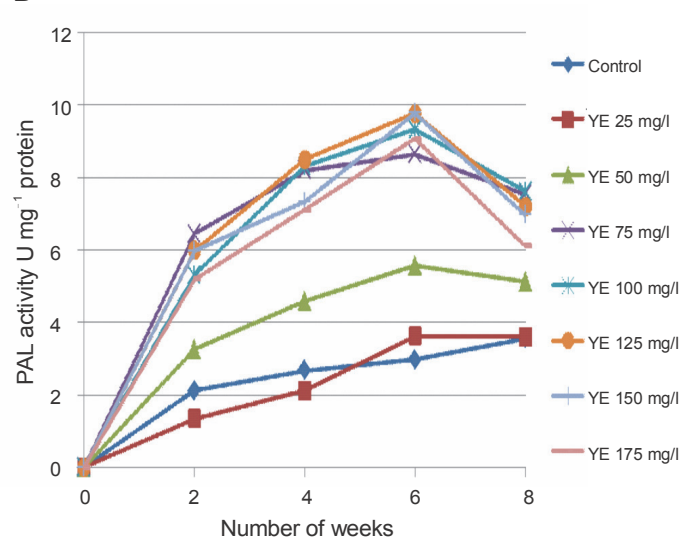

Fig. 4. A) Effect of different concentrations of YE treatment on phenylalanine ammonia lyase (PAL) activity; B) Time-course changes in PAL activity at different concentrations of YE; values represent mean $\pm \mathrm{SD}(n=3)$; values marked with different letters are significantly different from each other and from the control

A

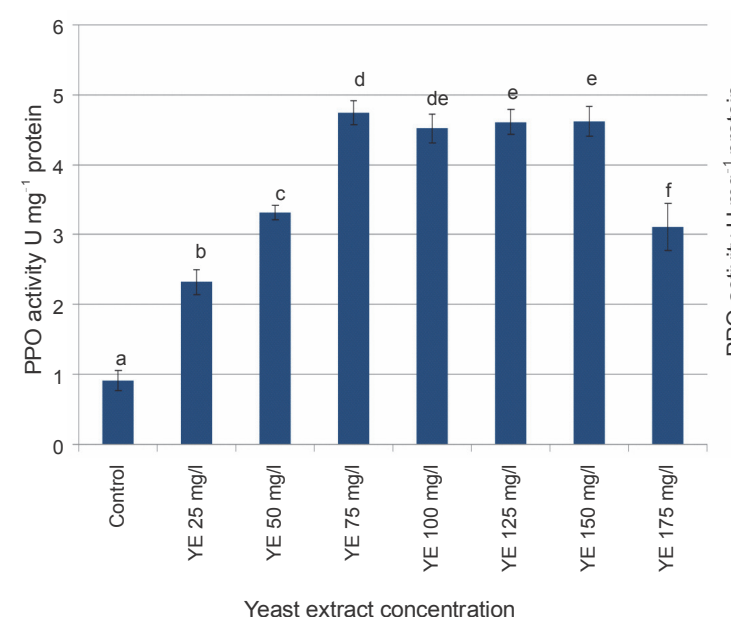

B

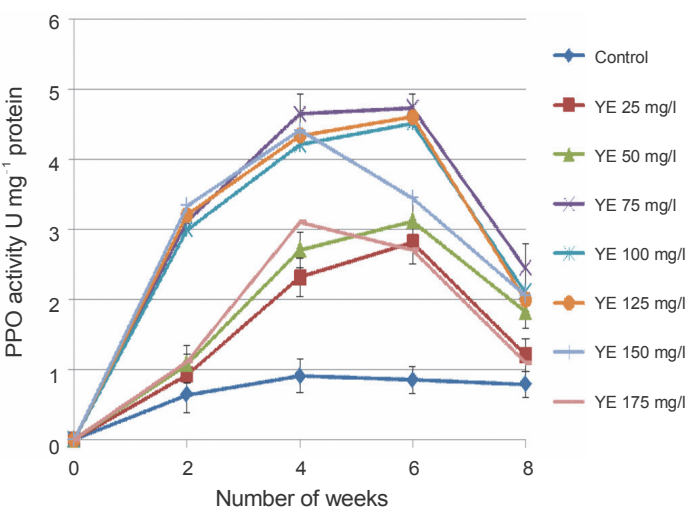

Fig. 5. A) Effect of different concentrations of YE treatment on polyphenoloxidase (PPO) activity; B) time-course changes in PPO activity at different concentrations of YE; values represent mean $\pm \mathrm{SD}(n=3)$; values marked with different letters are significantly different from each other and from the control

Changes in the POD activity of all YE treated samples were significantly different from those of the control (Fig. 6A). Time-course analysis revealed that the maximum POD activity was observed at 6 weeks with all YE concentrations ranging from $25 \mathrm{mg} / 1$ to $125 \mathrm{mg} / 1$ (Fig. $6 \mathrm{~B}$ ). At YE concentrations of $150 \mathrm{mg} / \mathrm{l}$ and $175 \mathrm{mg} / \mathrm{l}, \mathrm{POD}$ activities started to decline (19.7 $\mathrm{U} \mathrm{mg}^{-1}$ and $17.2 \mathrm{U} \mathrm{mg}^{-1}$ protein, respectively) after 4 weeks (Fig. 6B).

Such an early decrease in the activities of the antioxidant enzymes PPO and POD at higher concentrations ( $150 \mathrm{mg} / \mathrm{l}$ and $175 \mathrm{mg} / \mathrm{l}$ ) of YE might be due to the fact that the callus cultures are adversely affected at high concentrations of YE. The stress posed by the YE elicitor proves to be detrimental and impacts many vital proteins involved in the metabolism, disrupting defense processes such as antioxidant enzyme activities and declining flavonoid production.

\section{Effect of YE on the antioxidant activity of G. glabra callus extracts}

Flavonoids constitute the main components of the antioxidant system in plants due to their strong redox 

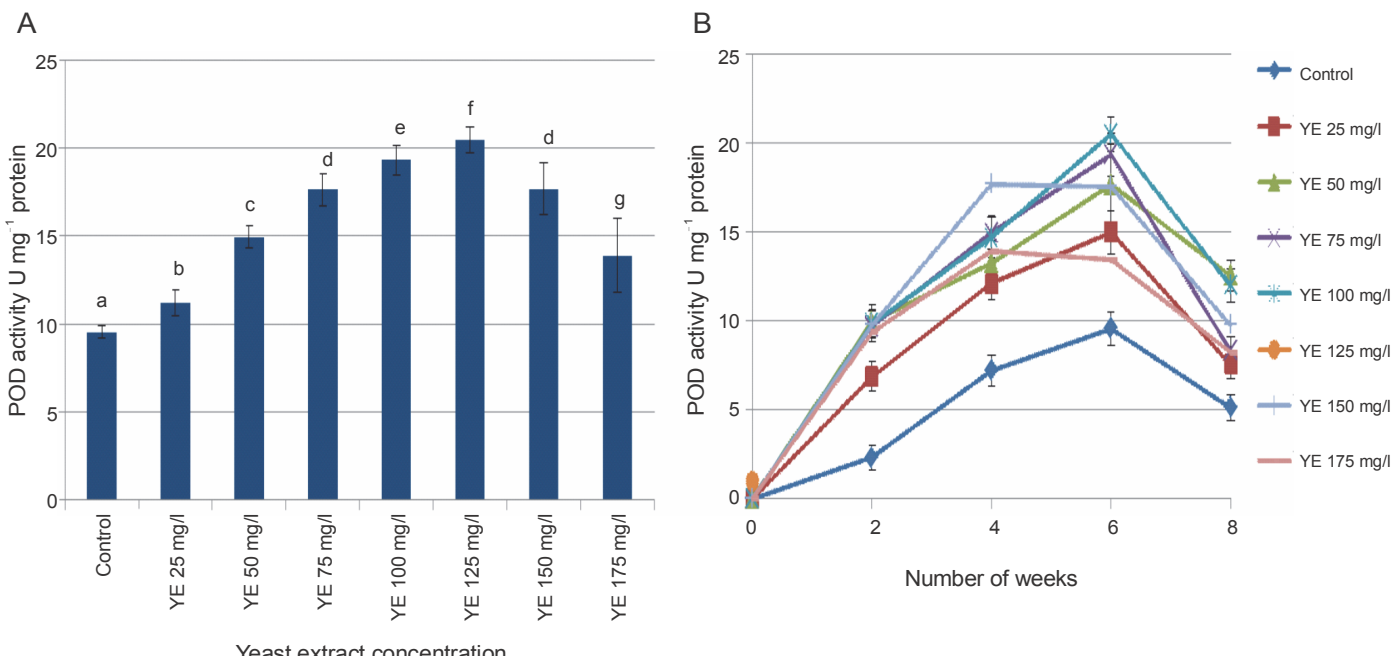

Fig. 6. A) Effect of different concentrations of YE treatment on peroxidase (POD) activity; B) time-course changes in POD activity at different concentrations of YE; values represent mean $\pm \mathrm{SD}(n=3)$; values marked with different letters are significantly different from each other and from the control
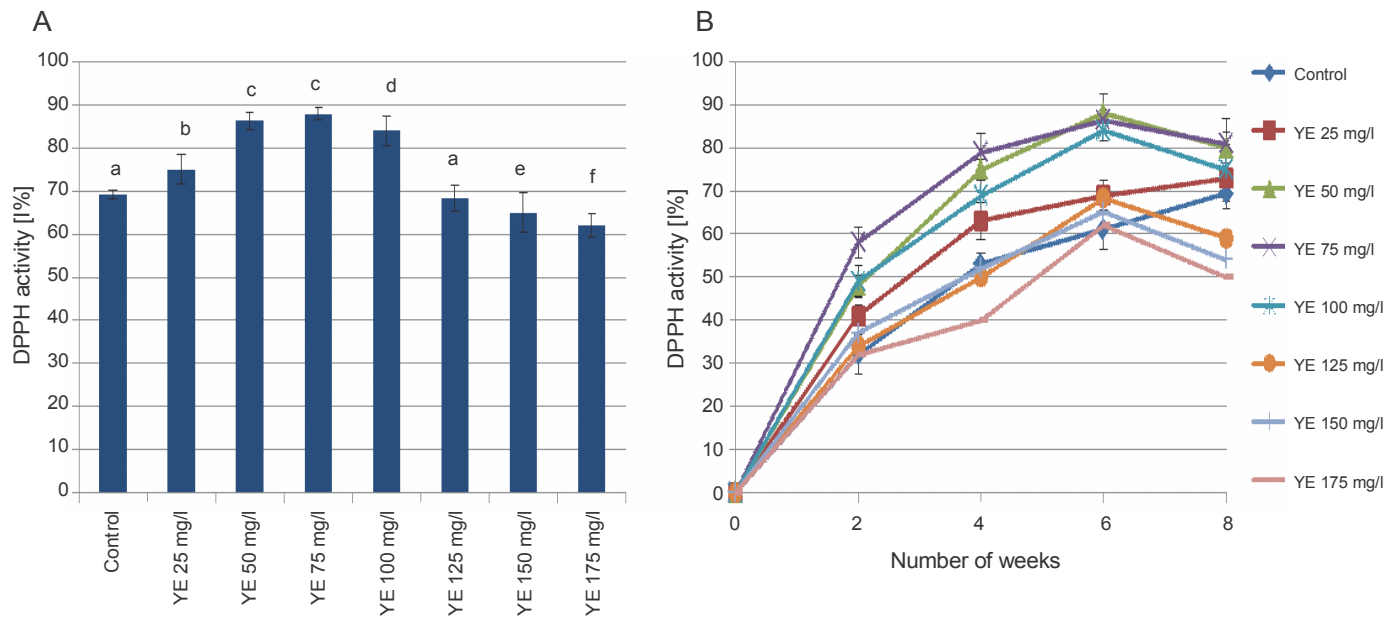

Yeast extract concentration

Fig. 7. A) Effect of different concentrations of YE treatment on 2,2-diphenyl-1-picrylhydrazyl scavenging activity; B) time-course changes in radical scavenging activity at different concentrations of YE; values represent mean \pm SD values marked with different letters are significantly different from each other and from the control

properties (Panche et al., 2016). $\mathrm{DPPH}^{\bullet}$ radical scavenging activity of flavonoids was used as a direct measure of the antioxidant potential of flavonoids in elicited callus cultures of G. glabra. Callus extracts treated with YE concentrations (from 25 to $125 \mathrm{mg} / \mathrm{l}$ ) showed a significant increase in $\mathrm{DPPH}^{\circ}$ radical scavenging activity when compared to that of control and the highest $\mathrm{DPPH}^{\circ}$ radical scavenging activity (I $\%=88$ ) was obtained with $75 \mathrm{mg} / \mathrm{l} \mathrm{YE} \mathrm{(Fig.} \mathrm{7A).} \mathrm{Time-course} \mathrm{analysis} \mathrm{showed} \mathrm{that}$ the maximum $\mathrm{DPPH}^{\circ}$ scavenging potential $(\mathrm{I} \%=73.1)$ of the callus extracts treated with $25 \mathrm{mg} / \mathrm{l} \mathrm{YE}$ was observed at 8 weeks, and for the rest of the treatments at 6 weeks of culture (Fig. 7B).

The YE-treated callus were also examined for their reducing power by assessing the amount of the reduction of $\mathrm{Fe}^{3+}$ to $\mathrm{Fe}^{2+}$ (Fig. 8). The reducing power of the extracts increased with increasing concentrations of $\mathrm{YE}$ but considerably decreased at $175 \mathrm{mg} / \mathrm{l}$ (Absorbance $=$ 0.85). According to previous findings, the exogenous application of elicitors mimics the response of a patho- 
A

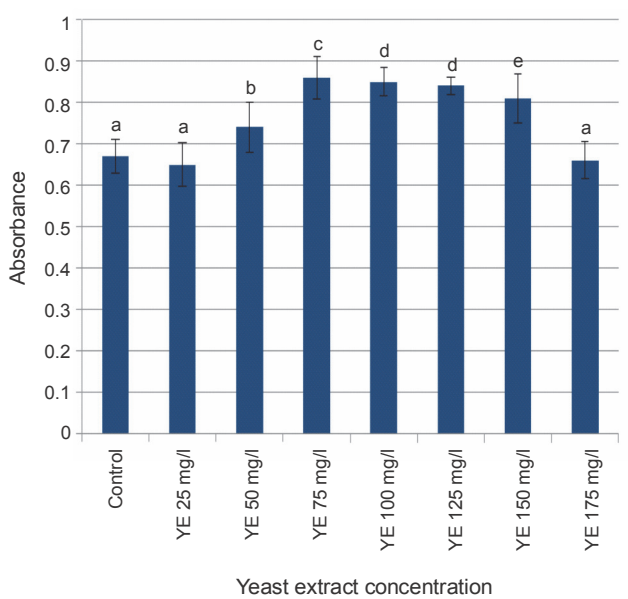

B

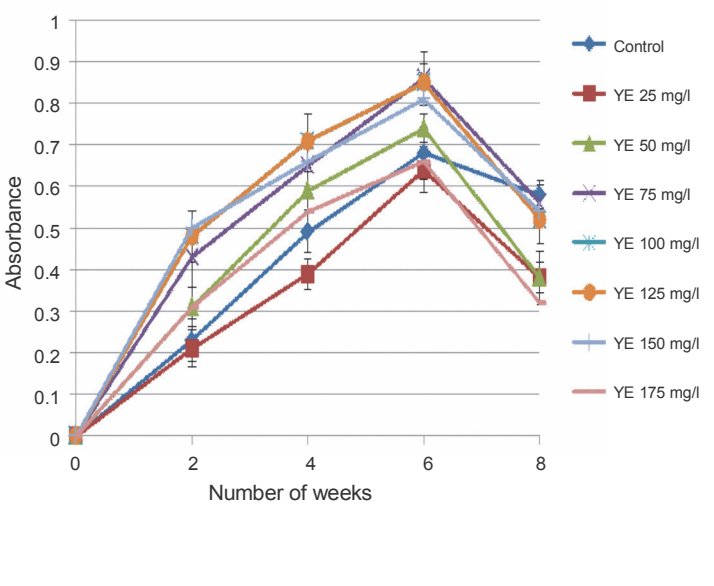

Fig. 8. A) Effect of different concentrations of YE treatment on reducing power; B) time-course change in reducing power at different concentrations of YE; values represent mean $\pm \mathrm{SD}(n=3)$; values marked with different letters are significantly different from each other and from the control

gen attack or a wound signal which triggers the defense response in plants by inducing oxidative burst (Manivannan et al., 2016). The oxidative perturbation in the cells further results in the accumulation of reactive oxygen species $\left(\mathrm{O}_{2^{-}}\right.$and $\left.\mathrm{H}_{2} \mathrm{O}_{2}\right)$. Antioxidants provide the first line of defense against elevated levels of ROS. Therefore, the elicitor increased the accumulation of major antioxidant compounds such as flavonoids in callus cultures. In the present study, the result of the free radical scavenging activity was in accordance with flavonoid contents, which suggests that these are potent antioxidants and free radical scavengers.

\section{Conclusions}

The elicitation of GCCs with the biotic elicitor YE caused an early and direct defense response due to the activation of phenylpropanoid metabolism and significantly enhanced the synthesis of therapeutically important flavonoids licoisoflavone $\mathrm{B}$, licochalcone $\mathrm{A}$, and liquirtigenin. It has been previously reported that supplementation of $\mathrm{YE}$ as an elicitor in callus not only enhanced the production of flavonoids and phenolic compounds, but also induced PAL activity (Al-Gendy et al., 2016). In the present research, the secondary metabolism in G. glabra callus was effectively upregulated while supplementing $75 \mathrm{mg} / \mathrm{l} \mathrm{YE}$ as elicitor, and more than 2 -fold increase in each of the three anti-cancerous flavonoids was obtained. The maximum production of these flavonoids occurred at the callus age of 6 weeks when the cultures were at their highest GI and showed the highest levels of metabolic activity. An exogenous application of the YE elicitor triggered a defense response in plants by inducing an oxidative burst, consequently eliciting the activity of antioxidant enzymes PPO and POD. The oxidative perturbation in the cells also resulted in the over-production and simultaneous accumulation of the three flavonoids, which could scavenge the free radicals and combat the elicitor stress.

Higher concentrations of YE (125-175 mg/l) not only induced apoptotic events strongly, but were also instrumental in expediting the senescence and decline of the cultures, resulting in decrease in the production of the flavonoids. Thus, it was concluded that $75 \mathrm{mg} / 1$ of $\mathrm{YE}$ proved to be the most effective elicitor concentration for obtaining enhanced production of anti-cancerous flavonoids licoisoflavone $\mathrm{B}$, licochalcone $\mathrm{A}$, and liquirtigenin in G. glabra callus cultures.

\section{Acknowledgments}

The authors are thankful to Mr. Ajai Kumar, Advanced Instrumentation Research Facility (AIRF), University Science Instrumentation Centre, JNU, New Delhi, for his support which enabled us to carry out the GC-MS analysis of the sample.

\section{References}

Abass M.H. (2016) Responses of date palm (Phoenix dactylifera L.) callus to biotic and abiotic stresses. Emirates J. Food Agric. 11: 66-74.

Abraham F., Bhatt A., Keng C.L., Indrayanto G., Sulaiman S.F. (2011) Effect of yeast extract and chitosan on shoot pro- 
liferation, morphology and antioxidant activity of Curcuma mangga in vitro plantlets. Afr. J. Biotechnol. 10: 7787-7795.

Adam A.L., Bestwick C.S., Barna B., Mansfield J.W. (1995) Enzymes regulating the accumulation of active oxygen species during the hypersensitive reaction of bean to Pseudomonas syringae pv. Phaseolicola. Planta 97: 240-249.

Al-Gendy A.A., Ali R.M., Hamdan D.I. and Abdel-Ghani A.E.S. (2016) Elicitation induced flavonoids, phenolic constituents, antioxidant and cytotoxic activities of Artemisia monosperma callus cultures. J. Med. Plants Res. 10: 717-731.

Ayebe S., Iida K., Furaya T. (1986) Stress-induced formation of echinatin and a metabolite, 5-prenyl-licodione, in cultured Glycyrrhiza echinata cells. Phytochem. 25: 2803-2806.

Bradford M.M. (1976) A rapid and sensitive method for the quantitation of microgram quantities of protein utilizing the principle of protein-dye binding. Analyt. Biochem. 72: 248-254.

Cakir O., Ari S. (2009) Defensive and secondary metabolism in Astragalus chrysochlorus cell cultures, in response to yeast extract stressor. J. Environ. Biol. 30: 51-55.

Chen H., Chen F., Chiu F.C.K., Lo C.M.Y. (2001) The effect of yeast elicitor on the growth and secondary metabolism of hairy root cultures of Salvia miltiorrhiza. Enzym. Microb. Technol. 28: 100-105.

Chen X., Liu Z., Meng R., Shi C., Guo N. (2017) Antioxidative and anticancer properties of Licochalcone $A$ from licorice. J. Ethnopharmacol. 198: 331-337.

Chittoor J.M., Leach J.E., White F.F. (1997) Differential induction of a peroxidase gene family during infection of rice by Xanthomonas oryzae pv. oryzae. Mol. Plant Microbe Interact. 1: 861-871.

El-Nabarawy M.A., El-Kafafi S.H., Hamza M.A., Omar M.A. (2015) The effect of some factors on stimulating the growth and production of active substances in Zingiber officinale callus cultures. Ann. Agricult. Sci. 60: 1-9.

Fu Y., Hsieh T.C., Guo J., Kunicki J., Lee M.Y., Darzynkiewicz Z., Wu J.M. (2004) Licochalcone-A, a novelflavonoid isolated from licorice root (Glycyrrhiza glabra), causes G2 and lateG1 arrests in androgen-independent $P C-3$ prostate cancer cells. Biochem. Biophys. Res. Commun. 322: 263-270.

George E.F., Hall M.A., Klerk G.J. (2008) The components of plant tissue culture media II: organic additions, osmotic and $\mathrm{pH}$ effects, and support systems. [in:] Plant propagation by tissue culture. Ed. George E.F., Hall M.A., De Klerk G.J., $3^{\text {rd }}$ ed. Springer: $115-173$.

Hayashi H., Huang P., Inoue K. (2003) Up-regulation of soyasaponin biosynthesis by methyl Jasmonate in cultured cells of Glycyrrhiza glabra. Plant Cell Physiol. 44: 404-411.

Hayashi H., Hiraoka N., Ikeshiro Y. (2005) Differential regulation of soyasaponin and betulinic acid production by yeast extract in cultured licorice cells. Plant Biotechnol. 22: 242-244.

Hinneburg I., Dorman H.D., Hiltunen R. (2006) Antioxidant activities of extracts from selected culinary herbs and spices. Food chem. 97: 122-129.

Hong M.L.K., Bhatt A.R.V.I.N.D., Ping N.S., Keng C.L. (2012) Detection of elicitation effect on Hyoscyamus niger L. root cultures for the root growth and production of tropane alkaloids. Rom. Biotech. Lett. 17: 7340-7351.

Inami K., Mine Y., Tatsuzaki J., Mori C., Mochizuki M. (2017) Isolation and characterization of antimutagenic components of Glycyrrhiza aspera against $\mathrm{N}$-methyl- $\mathrm{N}$-nitrosourea. Genes Environment. 39: 5.

Ishikava A., Kitamura Y., Ozeki Y., Watanabe M. (2007) Different responses of shoot and root cultures of Glehnia littoralis to yeast extract. J. Nat. Med. 61: 30-37.

Iqbal J., Abbasi B.A., Mahmood T., Kanwal S., Ali B., Shah S.A., Khalil A.T. (2017) Plant-derived anticancer agents: $A$ green anticancer approach. Asian Pacific J. Tropical Biomed. 7: 1129-1150.

Jacobs E.C. (2018) Potential therapeutic effects of phytochemicals and medicinal herbs for cancer prevention and treatment. Arch. General Internal Med. 2: 44-48.

Liu C., Wang Y., Xie S., Zhou Y., Ren X., Li X., Cai Y. (2011) Liquiritigenin induces mitochondria-mediated apoptosis via cytochrome $c$ release and caspases activation in $\mathrm{HeLa}$ Cells. Phytother. Res. 25: 277-283.

Ma X., Yu H. (2006) Cancer issue: global burden of cancer. The Yale J. Biol. Med. 79: 85-96.

Milosevic N., Slusarenko A.J. (1996) Active oxygen metabolism and lignification in the hypersensitive response in bean. Physiol. Mol. Plant Pathol. 49: 143-158.

Naik P.M., Al-Khayri J.M. (2016) Abiotic and biotic elicitors - role in secondary metabolites production through in vitro culture of medicinal plants. [in:] Abiotic and biotic stress in plants-recent advances and future perspectives. IntechOpen.

Panche A.N., Diwan A.D., Chandra S.R. (2016) Flavonoids: an overview. J. Nutrit. Sci. 5: 11-19.

Park M.R., Kim S.G., Cho I.A., Oh D., Kang K.R., Lee S.Y., Moon S.M., Cho S.S., Yoon G., Kim C.S., Oh J.S. (2015) Licochalcone-A induces intrinsic and extrinsic apoptosis via ERK1/2 and p38 phosphorylation-mediated TRAIL expression in head and neck squamous carcinoma FaDu cells. Food Chem. Toxicol. 77: 34-43.

Pourcel L., Routaboul J.M., Cheynier V., Lepiniec L., Debeaujon I. (2007) Flavonoid oxidation in plants: from biochemical properties to physiological functions. Trends Plant Sci. 12: 29-36.

Ramakrishna A., Ravishankar G.A. (2011) Influence of abiotic stress signals on secondary metabolites in plants. Plant Signal. Behavior 6: 1720-1731.

Savatovic S.M., Cetković G.S., Canadanović-Brunet J.M., Sjilas S.M. (2012) Kinetic behaviour of the DPPH radical-scavenging activity of tomato waste extracts. J. Serb. Chem. Soc. 77: 1381-1389.

Schneider S., Ullrich W.R. (1994) Differential induction of resistance and enhanced enzyme activities in cucumber and tobacco caused by treatment with various abiotic and biotic inducers. Physiol. Mol. Plant Pathol. 45: 291-304.

Shreya Dave H.A., Jain N.K. (2016) Assessment of anticancer properties of few medicinal plants. J. Pharmacogn. Phytochem. 5: 46. 
Soffan A., Alghamdi S.S., AldawoodA.S.(2014) Peroxidase and polyphenol oxidase activity in moderate resistant and susceptible Vicia faba induced by Aphis craccivora (Hemiptera: Aphididae) infestation. J. Insect Sci. 14: 285.

Stewart R.J., Sawyeer B.J.B., Bucheli C.S., Robinson S.P. (2001) Polyphenol oxidase is induced by chilling and wounding pineapple. Aust. J. Plant Physiol. 28 :181-191.

Vijayalakshmi U., Shourie A. (2015) Elicitor induced flavonoid production in callus cultures of Glycyrrhiza glabra and regulation of genes encoding enzymes of the phenylpropanoid pathway. Der Pharmacia Lett. 7: 156-166.

Vijayalakshmi U., Shourie A. (2016a) Cinnamic acid supplementation regulates the production of licochalcone $A$, liquirtigenin and licoisoflavone B in Glycyrrhiza glabra callus cultures. Internat. J. Phytomed. 8: 343-352.

Vijayalakshmi U., Shourie A. (2016b) Remedial effect of ascorbic acid and citric acid on oxidative browning of Glycyrrhiza glabra callus cultures. BioTechnologia 97: 179-186.

Vijayalakshmi U., Shourie A. (2017) Standardization of conditions for extraction of flavonoids from Glycyrrhiza glabra callus cultures. Int. J. Pharma. Bio. Sci. 8: 272-277.

Vispute S., Khopade A. (2011) Glycyrrhiza glabra Linn. "Klitaka": a review. Int. J. Pharma. Bio. Sci. 2: 42-51.

Wang H., Oo Khor T., Shu L., Su Z.Y., Fuentes F., Lee J.H., Tony Kong A.N. (2012) Plants vs. cancer: a review on natural phytochemicals in preventing and treating cancers and their druggability. Anti-Cancer Agents Med. Chem. 12: 1281-1305.
Wang D., Lu J., Liu Y., Meng Q., Xie J., Wang Z., Teng L. (2014) Liquiritigenin induces tumor cell death through mitogen-activated protein kinase-(MPAKs-) mediated pathway in hepatocellular carcinoma cells. BioMed Res. Internat. 2: 234-248 .

Wuttke W., Jarry H., Seidlová-Wuttke D. (2007) Isoflavones safe food additives or dangerous drugs. Ageing Res. Rev. 6: 150-188.

Yao K., Chen H., Lee M.H., Li H., Ma W., Peng C., Song N.R., Lee K.W., Bode A.M., Dong Z., Dong Z. (2014) Licochalcone $A$, a natural inhibitor of c-Jun N-terminal kinase 1. Cancer Prevent. Res. 7: 139-149.

Zhang Y.Y., Huang C.T., Liu S.M., Wang B., Guo J., Bai J.Q., Fan X.J., Jia Y.S (2016) Licochalcone $A$ exerts antitumor activity in bladder cancer cell lines and mice models. Tropical J. Pharmaceut. Res. 15: 1151-1157.

Zhang X., Liu C.J. (2015) Multifaceted regulations of gateway enzyme phenylalanine ammonia-lyase in the biosynthesis of phenylpropanoids. Mol. Plant. 8: 17-27.

Zhou M., Higo H., Cai Y. (2010) Inhibition of hepatoma 22 tumor by Liquiritigenin. Phytother. Res. 24: 827-833.

Zieslin N., Ben Zaken R. (1993) Peroxidase activity and presence of phenolic substances in peduncles of rose flowers. Plant Physiol. Biochem. 31: 333-339. 